Article

\title{
Field Test and Numerical Simulation for Coordinated Deformation of New Subgrade and Old Embankment Adjacent to River
}

\author{
Jihong Wei ${ }^{1}$, Zezhuo Song ${ }^{1}$, Yuxia Bai ${ }^{1}$, Jin Liu ${ }^{1} *$ (D), Debi Prasanna Kanungo ${ }^{2}$ and \\ Shaorui Sun 1 \\ 1 School of Earth Sciences and Engineering, Hohai University, Nanjing 210098, China; \\ weijhhhu@163.com (J.W.); szzhhu@163.com (Z.S.); byxhhu@163.com (Y.B.); sunsrhhu@163.com (S.S.) \\ 2 CSIR-Central Building Research Institute (CBRI), Roorkee 247667, India; debi.kanungo@gmail.com \\ * Correspondence: jinliu920@163.com or mydream@hhu.edu.cn; Tel.: +86-139-1397-6590
}

Received: 29 October 2018; Accepted: 20 November 2018; Published: 22 November 2018

\begin{abstract}
With the development of the economy in China, original roads may be unable to cope with the existing traffic. The expansion of the old embankment is the core problem for road expansion. Soft foundation differential settlements and pavement cracking along the joint between the new subgrade and old embankment often emerge after construction, especially during the operational period of the road. The Binjiang Avenue Project in Nanjing, China, is taken as a research example in this paper, and a typical test zone of about $300.0 \mathrm{~m}$ in length was selected to conduct research work through in-situ tests. The coordinated deformations of the subgrade combined with the old embankment under conditions of consolidation by drainage were researched using in-situ tests and numerical modeling. During the process of numerical modeling, the vertical drainage system in the compressible soft ground layers was simplified to be represented as the drainage band model and the equivalent sand-wall model. In addition, a soft ground creep model was adopted to calculate the deformation of the subgrade with the construction process. A comparison of the results between field tests and numerical simulations was carried out. The results show that there is good uniformity for both. Based on the results, three indexes for the new and old subgrade, such as the differential settlement, total settlement and post-settlement, should be viewed as the basis for the design and construction of the new subgrade and old embankment. Additionally, it was found that the soft ground model, drainage band model and equivalent sand-wall model are all completely suitable for the numerical modeling of the soft ground reinforcement subgrade. These results also provide a theoretical basis for the construction method of similar projects.
\end{abstract}

Keywords: embankment; drainage band model; equivalent sand-wall model; creep mode; field test

\section{Introduction}

The widening of embankments and pavements has been increasingly undertaken to improve traffic volume. During the process of adding a new embankment to the existing embankment, additional stresses and deformations can develop under both the new and existing embankments [1,2]. Differential settlement often occurs between and within the widened portion and the existing embankments [3,4]. After construction for widening the embankment, pavement damage may occur due to differential settlement, such as longitudinal cracks or drop-off of pavement sections [5-8], especially during the operational period of the road. Therefore, the deformation mechanics should be studied in order to avoid the emergence of these problems if possible.

Recently, field tests and numerical analysis have been used to study the deformation mechanics for embankment projects [9-14]. Higo et al. [15] determined the three-dimensional strain localization 
of water saturated clay, using a numerical simulation with an elasto-viscoplastic model. Han et al. [16] studied the numerical analysis of foundation columns to support the widening of embankments. Oka et al. [17] analyzed the damage patterns of river embankments due to the 2011 earthquake off the pacific coast of Tohoku, and established numerical modeling of the deformation of river embankments with a clayey subsoil layer. Kamash and Han [18] studied the displacements of column-supported embankments over soft clay after widening, considering soil consolidation and column layout, by using numerical analysis. These research results have indicated that the selection of appropriate calculation models combined with field tests is important to the successful design and construction of widened embankment projects.

In this paper, the widened embankments of Binjiang Avenue in Nanjing city, China, were studied. Field tests and a numerical simulation were conducted to analyze the coordinated deformations of the subgrade combined with the old embankment, under conditions of drainage consolidation. Dynamic deformation of the subgrade was monitored during the construction of the subgrade, and the horizontal and vertical displacements occurring with the process of construction were analyzed. The post-settlement was forecasted based on the monitoring data using the three-point method and finite element method. During the process of numerical simulation, the vertical drainage system in the compressible soft ground layers was simplified as the drainage band model and equivalent sand-wall model. Meanwhile, a soft ground creep model was adopted to calculate the deformation of the subgrade with the construction process. The comparison in results between field tests and the numerical simulation were also carried out.

\section{Field Test and Analysis}

\subsection{Research Zone and Construction Procedure}

The research zone is a typical section under geological conditions. The field test zone is shown in Figure 1. There were two test sections of $\mathrm{K} 12+850$ and $\mathrm{K} 13+010$ in the research zone. In this study, $\mathrm{K} 12+850$ was selected as test section.

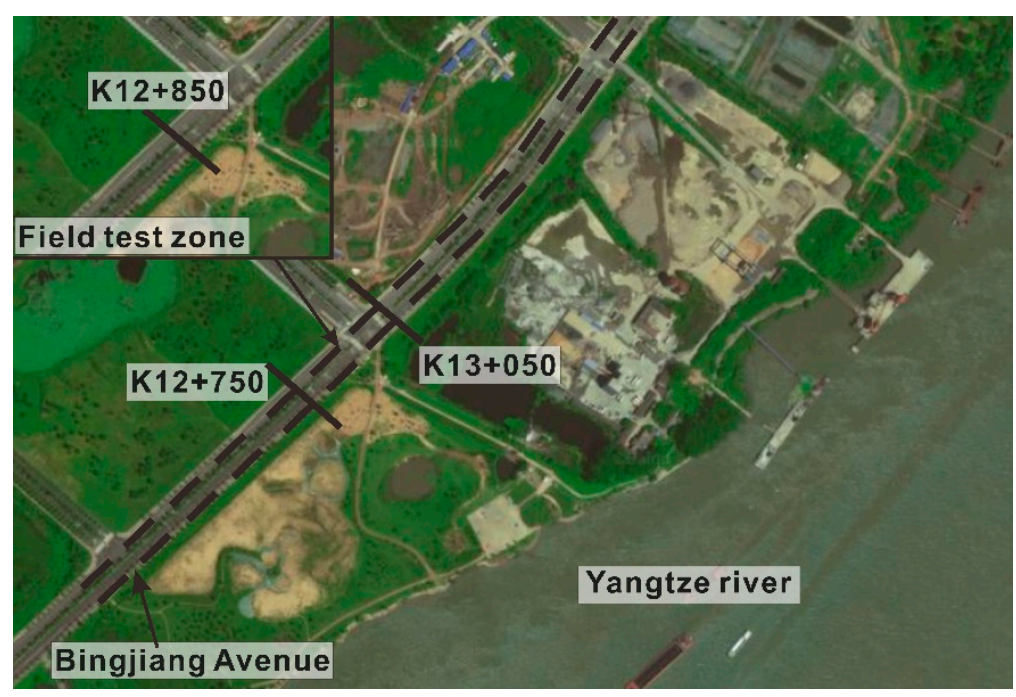

Figure 1. The field test zone.

The thickness of soft ground in the test zone was $14.0-18.0 \mathrm{~m}$. A plastic drainage band was used as a vertical drainage system. The plastic drainage band was arranged with an equilateral triangle structure with $1.2 \mathrm{~m}$ spacing, $4 \mathrm{~mm}$ thickness and $100 \mathrm{~mm}$ width. The treatment depth of the soft soil was $18 \mathrm{~m}$, and the filling height of the monitoring section was 7.0-9.0 m.

The drainage consolidation was selected to reinforce the soft foundation. The process of field construction is shown in Table 1 and Figure 2. The monitoring section and layout of the monitoring 
instruments in the test zone are shown in the Figure 3. There were two deep horizontal deformation instruments, which include the settlement plate and level gauge, and two vertical deformation instruments, which include the survey tube and survey instrument used. The CX1-1 was used to monitor the horizontal deformation of the new subgrade, and the CX1-2 was used to monitor the horizontal deformation of the old embankment affected by the new subgrade. The CJ1-1 was used to monitor the settlement of soft ground below the hydraulic fill sand, and the CJ1-2 was used to monitor the settlement of the old embankment.

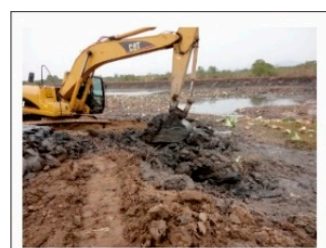

( a )

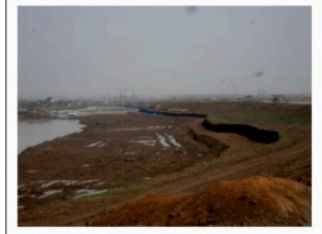

(e)

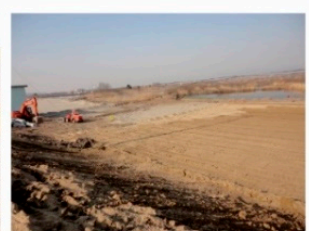

( b )

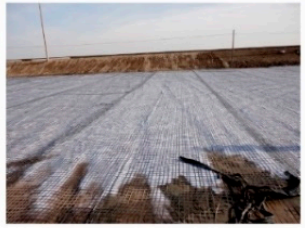

( f)

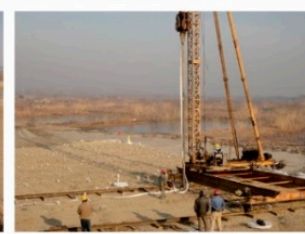

(c)

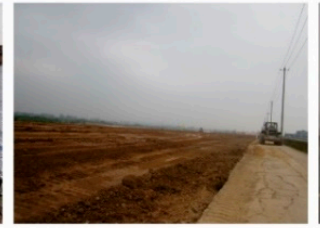

( g)

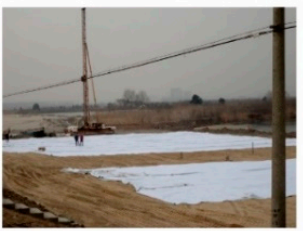

(d)

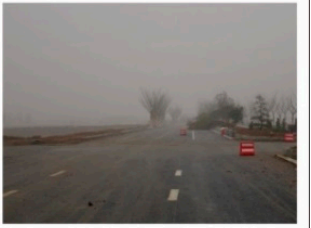

( h )

Figure 2. Procedure of construction: (a) Mechanical dredging; (b) Backfill sand; (c) Plastic drainage board; (d) Geotextile laid; (e) Joining of new and old subgrades; (f) Geogrid laid; (g) Backfill clay; and (h) Pavement construction.

Table 1. Construction procedure of the test zone.

\begin{tabular}{|c|c|c|c|c|c|c|c|c|c|c|}
\hline \multirow{2}{*}{ Date } & \multicolumn{2}{|c|}{2010} & \multicolumn{8}{|c|}{2011} \\
\hline & $11.20 \sim 11.28$ & $12.22 \sim 1.22$ & 1.25 & $2.21 \sim 2.22$ & 3.2 & $3.11 \sim 3.12$ & 3.20 & $4.23 \sim 4.26$ & $7.2 \sim 10.15$ & $11.25 \sim$ \\
\hline Procedure & $\begin{array}{l}\text { Dredging and } \\
\text { hydraulic fill } \\
\text { sand }\end{array}$ & $\begin{array}{l}\text { Fill sand and } \\
\text { drainage band } \\
\text { construction }\end{array}$ & $\begin{array}{l}\text { hydraulic } \\
\text { fill sand } \\
50 \mathrm{~cm}\end{array}$ & $\begin{array}{l}\text { hydraulic } \\
\text { fill sand } \\
100 \mathrm{~cm}\end{array}$ & $\begin{array}{l}\text { hydraulic } \\
\text { fill sand } \\
100 \mathrm{~cm}\end{array}$ & $\begin{array}{l}\text { hydraulic } \\
\text { fill sand } \\
80 \mathrm{~cm}\end{array}$ & $\begin{array}{l}\text { hydraulic } \\
\text { fill sand } \\
50 \mathrm{~cm}\end{array}$ & $\begin{array}{l}\text { hydraulic } \\
\text { fill sand } \\
50 \mathrm{~cm}\end{array}$ & $\begin{array}{c}\text { Fill lime } \\
\text { clay } \\
1.3 \mathrm{~cm} \text {, } \\
20 \mathrm{~cm} / 7 \mathrm{~d}\end{array}$ & $\begin{array}{c}\text { Preload } \\
\text { soil } \\
1.3 \mathrm{~m}\end{array}$ \\
\hline
\end{tabular}

\subsection{Results Analysis of Field Test}

The horizontal displacements of section $\mathrm{K} 12+850$ under different construction periods as measured by CX1-1 and CX1-2 are shown in Figure 4. According to Figure 4, in an earlier stage of construction, horizontal displacement of the surface at the toe of the slope moves toward the embankment, while horizontal displacement of the deep shows lateral migration to the embankment. With the development of subgrade filling, both horizontal displacement of the surface at the toe of the slope and the deep show lateral migration to the embankment. The main reason for this is that the settlement of fill soil upside applies outward pressure on the soft soil in the lower part. At $5 \mathrm{~m}$ under the surface, which is the bottom of the deposit of the original river course and the top of the silt clay, the horizontal displacement achieves its maximum. This means that in the earlier stages, the filled soil is less influenced by extrusion than the soft soil in the lower part during construction, and the horizontal displacement monitoring at the top of the silt clay should be taken into account when soft soil is buried too deeply in the project. Meanwhile, under the silt clay, the horizontal displacement is smaller the deeper it gets. According to comparisons between CX1-1 and CX1-2, the horizontal displacement of the joint part of the road and embankment is smaller than that of the toe of the slope, meaning the new fill subgrade has little effect on the lateral deformation of the joint part of the road and embankment. At nearly $6 \mathrm{~m}$ height, which is the joint part of the new filled embankment and the slope of the old embankment, the horizontal displacement of the joint part of the road and embankment achieves its maximum, which means that lateral deformation easily mutates near the boundary of the soil, and a large lateral horizontal displacement can easily occur under the boundary. During filling, the rates 
of deep lateral horizontal displacement remain small and are never beyond the control standard of $5 \mathrm{~mm} /$ day. Up until 6 March 2012, the maximum deformation had not extended beyond $150 \mathrm{~mm}$, which suggests good stability of the embankment.
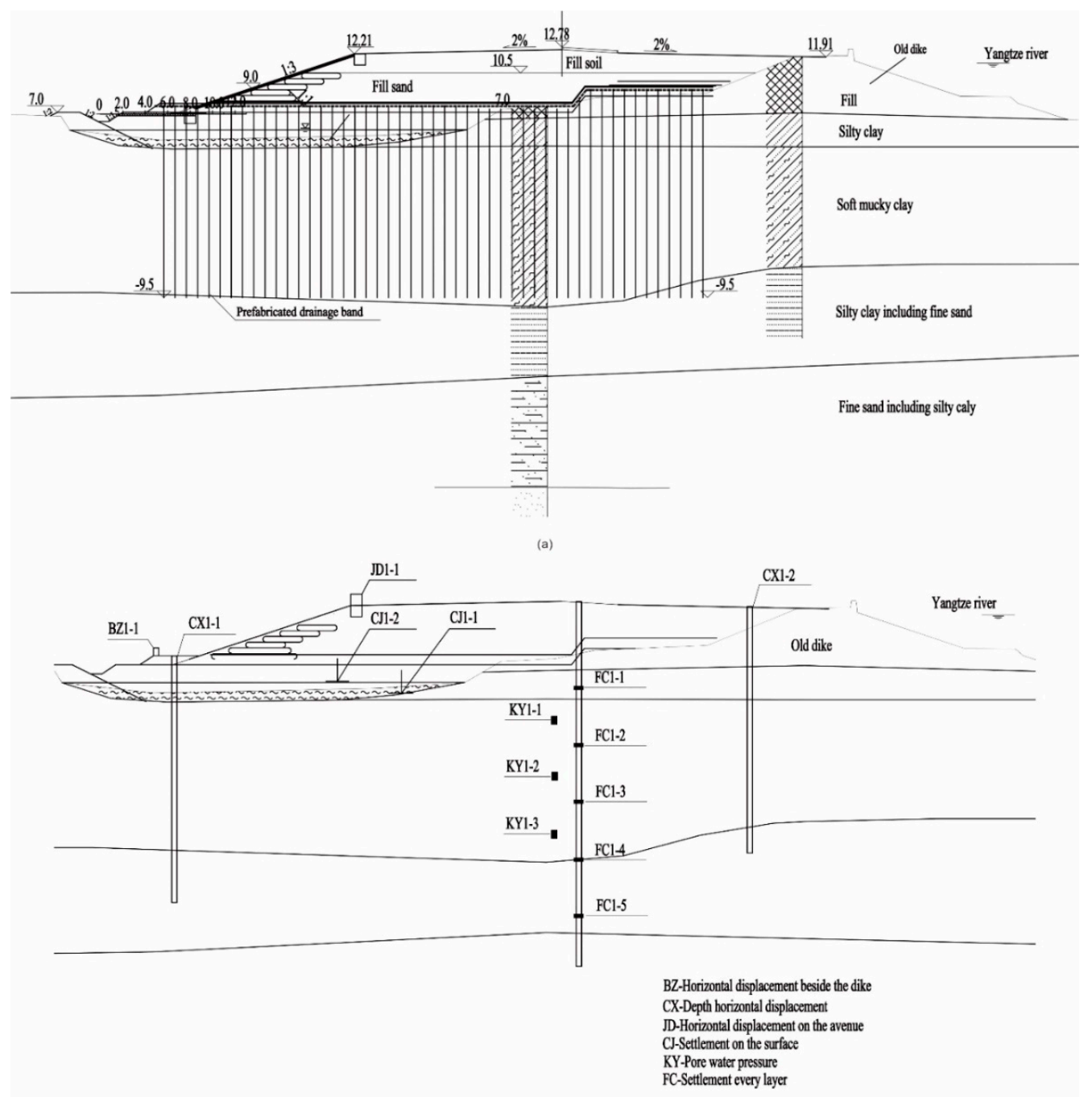

Figure 3. Monitoring section and layout of the monitoring instruments in the test zone: (a) Section $\mathrm{K} 12+850 ;(\mathbf{b})$ Layout of the monitoring instruments.

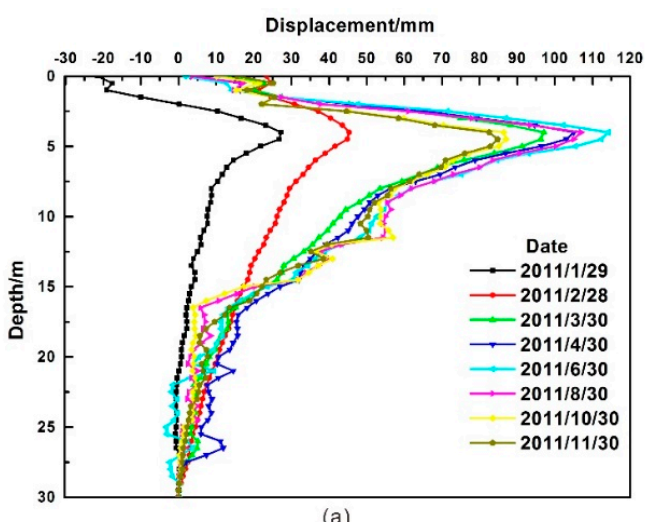

(a)

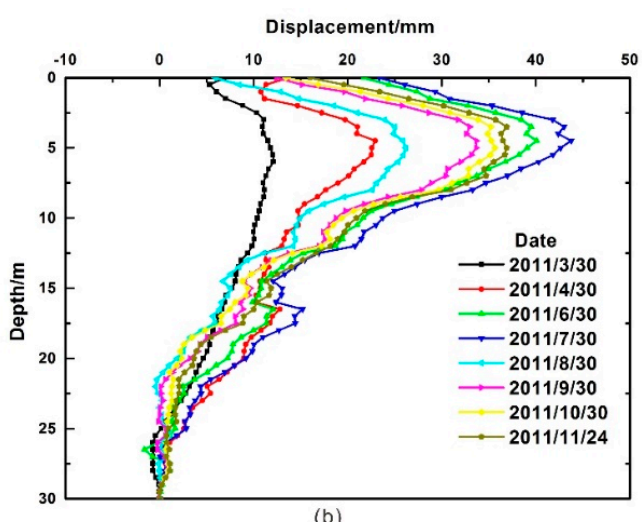

(b)

Figure 4. Deep horizontal displacement: (a) CX1-1; (b) CX1-2. 
The variation of settlement and embankment filling height of the $\mathrm{K} 12+850$ section in the field test up until 6 March 2012, is shown in Figure 5. As can be seen, the settlement of CJ1-1 is $1315.10 \mathrm{~mm}$ and CJ1-2 is $1295.97 \mathrm{~mm}$. The settlement in February is nearly $30 \sim 50 \mathrm{~mm}$, much larger than $5 \mathrm{~mm}$, and the settlement occurring every month is still very large. The final settlement of the embankment is predicted to be $1600 \mathrm{~mm}$ using the layer-wise summation method, so the settlement after construction is nearly $300 \mathrm{~mm}$, and there is some redundancy of settlement. The degree of consolidation is nearly $80 \%$ and the consolidation is good, but there is a long time of preloading before unloading. Meanwhile, according to the curve, the rate of settlement is large during loading and gradually decreases during preloading or intermission of loading, so the rate of loading should be controlled to prevent the instability of the embankment from loading too fast. In general, this means that the rate of settlement is too large when it is beyond $10 \mathrm{~mm} / \mathrm{d}$, but in total, the whole embankment is stable.

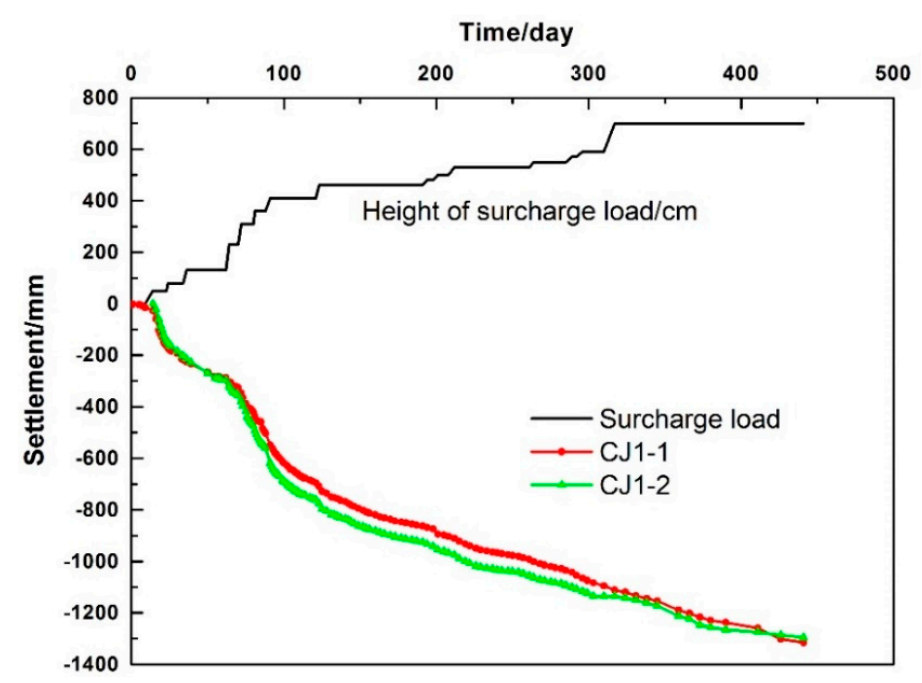

Figure 5. Variation of settlement and embankment filling height of the $\mathrm{K} 12+850$ section in the field test.

\subsection{The Prediction of Settlement}

Recently, many calculation methods have been used for the settlement of the soft foundation. In this study, the three-point method based on the hyperbola method [19] was selected. The schematic diagram of the three-point method and hyperbola method are shown in Figures 6 and 7 . When $t \rightarrow \infty$, the final settlement is calculated according to the following Formula:

$$
S_{\infty}=S_{1}+\frac{1}{\beta}=S_{1}+\frac{\left(S_{3}-S_{1}\right)\left(S_{2}-S_{1}\right)}{2\left(S_{2}-S_{1}\right)-\left(S_{3}-S_{1}\right)},
$$

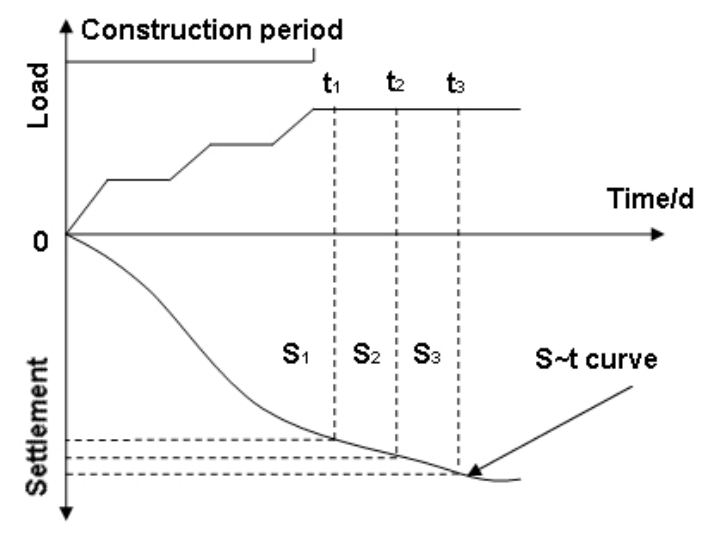

Figure 6. The schematic diagram of the three-point method. 


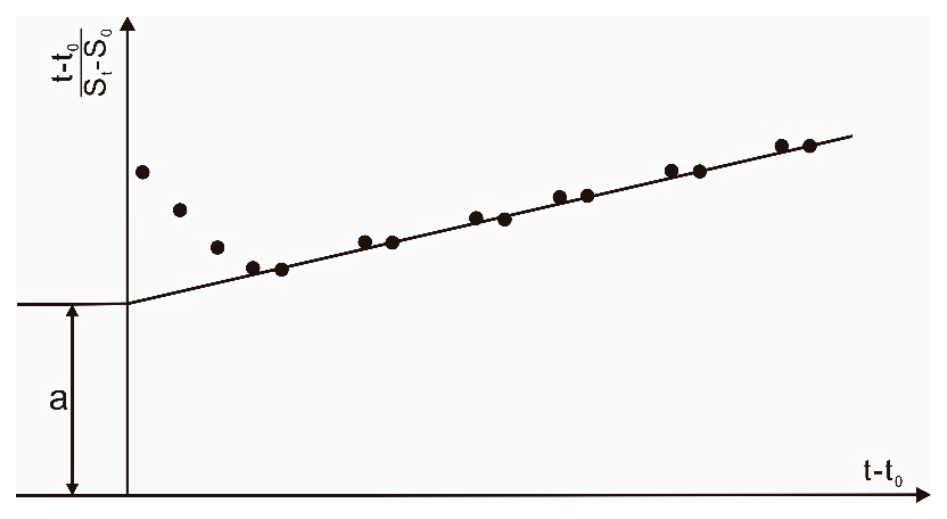

Figure 7. The diagram of the hyperbola method.

According to the test data, the three-point method based on the hyperbola method is used to predict late settlement. The late settlement prediction is shown in Table 2. It can be seen from Table 2 that the settlements of CJ1-1 in November 2012, December 2012, and January 2013 are $5.27 \mathrm{~mm}$, $4.53 \mathrm{~mm}$ and $3.93 \mathrm{~mm}$, respectively. For CJ1-1, in September, October, November and December 2012, the settlements are $5.36 \mathrm{~mm}, 4.69 \mathrm{~mm}, 4.13 \mathrm{~mm}$, and $3.68 \mathrm{~mm}$, respectively.

Table 2. The late settlement prediction.

\begin{tabular}{ccccccccccc}
\hline Date & & $\mathbf{2 0 1 2 . 9 . 1}$ & $\mathbf{2 0 1 2 . 1 0 . 1}$ & $\mathbf{2 0 1 2 . 1 1 . 1}$ & $\mathbf{2 0 1 2 . 1 2 . 1}$ & $\mathbf{2 0 1 3 . 1 . 1}$ & $\mathbf{2 0 1 3 . 2 . 1}$ & $\mathbf{2 0 1 3 . 3 . 1}$ & $\mathbf{2 0 1 3 . 4 . 1}$ & $\begin{array}{c}\text { Final } \\
\text { Settlement }\end{array}$ \\
\hline $\begin{array}{c}\text { Three-point } \\
\text { method (mm) }\end{array}$ & CJ1-1 & 1432.21 & 1439.66 & 1445.88 & 1451.15 & 1455.68 & 1459.61 & 1463.05 & 1466.10 & 1515.21 \\
\hline $\begin{array}{c}\text { Consolidation coefficient } \\
\text { method (mm) }\end{array}$ & 1356.40 & 1361.76 & 1366.45 & 1370.58 & 1374.26 & 1377.54 & 1380.50 & 1383.17 & 1436.35 \\
\hline
\end{tabular}

According to the unloading conditions: (1) The settlement after construction is less than $30 \mathrm{~cm}$ and this condition has been met; (2) monthly settlement is less than $5 \mathrm{~mm}$ for 2 consecutive months, which means the unloading should be in early February 2013, about 13 months after surcharge preloading. Preparation of the foundation settlement in the FORTRAN computer program (Hohai University, Nanjing, China) can be predicted according to the consolidation coefficients method, and it can be calculated by the consolidation coefficients method that the settlement in November 2011 was nearly $5.61 \mathrm{~mm}$, the settlement in December 2011 was nearly $5.12 \mathrm{~mm}$, the settlement in January 2013 was nearly $4.68 \mathrm{~mm}$, and the settlement in February 2013 was nearly $4.27 \mathrm{~mm}$. Therefore, according to the unloading condition, the monthly settlement is less than $5 \mathrm{~mm}$ for 2 consecutive months and the unloading should be in early March 2013-14 months after surcharge preloading. In total, taking the field test as an example, the unloading is nearly in late February 2013 and early March so that the surcharge preloading is nearly 14 months earlier.

\section{Numerical Simulation on Deformation of Embankment Combined with Subgrade}

\subsection{Calculation Model}

The software used in this study is Plaxis (Delft University, Netherlands) and the version is 7.1. The basic characteristics of the creep model of soft foil are as follows: stress-related stiffness; the difference between main loading and unload-reload; secondary compression; memory of pre-consolidation stress; disruptive behavior based on the Mohr-Coulomb criterion; and shallow clay. The parameters of the creep model of soil include dry severe $\gamma_{d}$, saturation severe $\gamma_{\text {sat }}$, horizontal permeability $K_{\mathrm{h}}$, vertical permeability $K_{\mathrm{v}}$, the corrected compression index $\gamma^{*}$, modified swelling index $k^{*}$, correction creep index $\mu^{*}$, cohesion $c$, friction angle $\varphi$, and expansion angle $\Psi$. The parameter calculation formulas of some individual parameters are as follows: 
(1) Fixed compression index:

$$
\lambda^{*}=\frac{C_{c}}{\left(1+e_{0}\right) \ln 10}
$$

where $C_{c}=\frac{e_{1}-e_{2}}{\lg p_{2}-\lg p_{1}}$ is the compression index.

(2) Modified swelling index:

$$
k^{*}=\frac{3\left(1-v_{u r}\right)}{\left(1+v_{u r}\right)} A=\frac{3\left(1-v_{u r}\right)}{\left(1+v_{u r}\right) \ln 10} \frac{C_{r}}{\left(1+e_{0}\right)},
$$

where $C_{r}$ is the swelling index, and $v_{u r}$ is the unload-reload poison ratio.

(3) Fixed creep index:

$$
\mu^{*}=\frac{C_{\alpha}}{\left(1+e_{0}\right) \ln 10}
$$

where $C_{\alpha}$ is the creep index.

\subsection{Initial Condition}

Because this problem relates to plane strain, the construction conditions of the roadbed model are: (1) Considering the settlement after filling, the height of filling plus the settlement are taken as the filling height of the section. (2) The surface of the ground is of free deformation, the left and right horizontal boundaries are subject to constraints, the end of the horizontal and vertical to the boundary are constrained, and the horizontal and vertical displacements are zero. (3) Considering the seepage boundary, the two vertical boundaries are impervious, the bottom layer of the model is sand that is permeable, and the upper boundary is permeable. (4) One metre below the surface of the original ground, the height is $6 \mathrm{~m}$. (5) The creep deformation of soft soil is considered. (6) The models are Mohr Coulomb and Soft Soil Creep.

\subsection{Simplified Calculation of the Plastic Drainage Plate}

Since the subgrade is considered as a plane strain problem, so the sand is transformed into the sand wall; the sand drain space and permeability coefficient of sand are in equivalent adjustment. After sand-drained ground is adjusted equally to sand wall subgrade, the degrees of consolidation in same depth or average degree of consolidation in any depth should be as equal as possible at any time. Plastic drainage plate uses the equivalent sand-wall method and equals 3D sand-drained ground to 2D sand wall subgrade. As vertical consolidation effects little on the consolidation degree of the sand wall, so the vertical permeability of the sand wall is equal with vertical permeability of undisturbed soil. To reflect the real situation of foundation reinforcement where possible, the principle of equal is used to calculate the half width of equivalent sand wall $B_{w}$, and then calculate the half width of sand wall B and horizontal penetration parameter of sand wall $k_{h p}$.

$$
\pi r_{w}^{2}=2 B_{w} \times \frac{\sqrt{3}}{2} d(\text { Triangular arrangement }) ; \pi r_{w}^{2}=2 B_{w} \times d(\text { Square arrangement }),
$$

where $r_{w}$ is the sand well radius (plastic drainage plate equals sand well radius), and $d$ is the sand drain space (plastic drainage plate equals impacted diameter).

When the plane strain problem of the vertical wall ground is equal with the ax symmetric problem of the sand-drained ground, the principle that the average consolidation degree is equal at the depth of $\mathrm{z}$ is used, and then it shows:

$$
\frac{k_{h p}}{k_{h a}}=\frac{8\left(B-b_{w}\right)^{2}}{3 d_{e}^{2} F_{a}}
$$


To make sure that the plane strain problem of vertical wall ground is equal with the ax symmetric problem of sand-drained ground, then $B_{r p}=B_{r a}$ is needed, so:

$$
\begin{gathered}
B=n^{2} B_{w}, \\
k_{h p}=\frac{8\left(B-B_{w}\right)^{2}}{3 d_{e}^{2} F_{a}} k_{h} \\
F_{a}=\left(\ln \frac{n}{s}+\frac{k_{h}}{k_{s}} \ln s-0.75\right) \frac{n^{2}}{n^{2}-1}+\frac{s^{2}}{n^{2}-1}\left(1-\frac{k_{h}}{k_{s}}\right)\left(1-\frac{s^{2}}{4 n^{2}}\right)+\frac{k_{h}}{k_{s}} \frac{1}{n^{2}-1}\left(1-\frac{1}{4 n^{2}}\right),
\end{gathered}
$$

where $n$ is the hole diameter ratio; $S$ is the smear factor; $k_{h}$ is the horizontal soil permeability; $k_{S}$ is the horizontal permeability coefficient of the smear zone soil; $r_{w}$ is the radius of the vertical drain; $r_{s}$ is the smear zone radius; $r_{e}$ is the valid radius of the effected zone; and $k_{w}$ is the permeability coefficient of the vertical drain.

The diameter and spacing of the sand well mainly depends on the characteristics of soft soil consolidation and the time requirement. Narrowing the spacing has a better effect than the lagging diameter, in terms of it being good for the sand drain to be both thin and dense in principle. However, the diameter of the sand drain has a certain relationship with the construction method. The hole diameter of the plastic drainage plate is width $\times$ thickness $(b \times \delta)$; the translation diameter is:

$$
d_{w}=\alpha \frac{2(b+\delta)}{\pi}
$$

where $\alpha$ is the reduction factor of the drain's permeable ability under the pressure of the surrounding soil, and would generally be $0.75 ; b$ and $\delta$ are the plastic drainage plate's width and thickness; and $d_{w}$ is the equivalent impact diameter.

The plastic drainage plate can be used as a vertical drain, and it can be arranged according to a square, plum shape, or equilateral triangle configuration, among others. An arrangement of squares and triangles are most commonly used. In design calculations, the vertical drain is usually replaced by a cylinder whose effective drainage diameter is $d_{e}$, and the relationship between $d_{e}$ with vertical drain spacing $\mathrm{d}$ is as follows:

$$
d_{e}=1.05 d \text { (Equilateral triangular arrangement); } d_{e}=1.128 d \text { (Square arrangement), }
$$

where $d_{e}$ is the effective drainage diameter of the drainage body, and $d$ is the spacing between the drainage.

\subsection{Model Parameter Selection}

$\mathrm{K} 12+850$ was taken as the test section. According to the Soft Foundation Treatment Plan, several parameters can be calculated after equaling the plastic drainage plate with the sand drain. The parameters used in the calculation model are shown in Tables 3-6.

Table 3. The model size parameters.

\begin{tabular}{ccccccccc}
\hline $\begin{array}{c}\text { Subgrade } \\
\text { Width } \\
(\mathbf{m})\end{array}$ & $\begin{array}{c}\text { Filling } \\
\text { Height } \\
(\mathbf{m})\end{array}$ & Gradient & $\begin{array}{c}\text { Plastic } \\
\text { Drainage Plate } \\
\text { Depth }(\mathbf{m})\end{array}$ & $\begin{array}{c}\text { Groundwater } \\
\text { Depth }(\mathbf{m})\end{array}$ & $\begin{array}{c}\text { Model } \\
\text { Width } \\
(\mathbf{m})\end{array}$ & $\begin{array}{c}\text { Early Backfill } \\
\text { Sand Depth } \\
(\mathbf{m})\end{array}$ & $\begin{array}{c}\text { Backfill } \\
\text { Sand Depth } \\
(\mathbf{m})\end{array}$ & $\begin{array}{c}\text { Lime Soil \& } \\
\text { Preloading Soil } \\
\text { Depth }(\mathbf{m})\end{array}$ \\
\hline 42 & 7 & $1: 3$ & $-10 \sim 7$ & 6 & 180 & $4 \sim 7$ & $7.5 \sim 12$ & $12 \sim 14$ \\
\hline
\end{tabular}

Table 4. The height of soil layers in the models.

\begin{tabular}{cccccc}
\hline Soil Layers & Plain Fill & Clay & Muddy Clay & Silty Clay & Fine Sand \\
\hline Height & $7 \mathrm{~m} \sim 12 \mathrm{~m}$ & $4 \mathrm{~m} \sim 7 \mathrm{~m}$ & $-10 \mathrm{~m} \sim 4 \mathrm{~m}$ & $-20 \mathrm{~m} \sim-10 \mathrm{~m}$ & $-30 \mathrm{~m} \sim-20 \mathrm{~m}$ \\
\hline
\end{tabular}


Table 5. Mohr coulomb model parameters.

\begin{tabular}{|c|c|c|c|c|c|c|c|c|c|}
\hline Parameters & $\begin{array}{l}\text { Plain } \\
\text { Fill }\end{array}$ & Clay & $\begin{array}{l}\text { Muddy } \\
\text { Clay }\end{array}$ & $\begin{array}{l}\text { Silty } \\
\text { Clay }\end{array}$ & $\begin{array}{l}\text { Fine } \\
\text { Sand }\end{array}$ & $\begin{array}{c}\text { Reclaimed } \\
\text { Sand }\end{array}$ & $\begin{array}{c}\text { Drainage } \\
\text { Coarse Sand }\end{array}$ & $\begin{array}{c}\text { Backfill } \\
\text { Clay }\end{array}$ & $\begin{array}{c}\text { Muddy Clay } \\
\text { between Sand } \\
\text { Wall }\end{array}$ \\
\hline$g_{\text {unsat }}\left(\mathrm{kN} / \mathrm{m}^{3}\right)$ & 18.03 & 17.74 & 17.84 & 17.84 & 18.72 & 19.01 & 19.7 & 20.07 & 17.84 \\
\hline$g_{\text {sat }}\left(\mathrm{kN} / \mathrm{m}^{3}\right)$ & 18.43 & 17.84 & 18.15 & 18.32 & 19.15 & 19.64 & 20.71 & 21.3 & 18.15 \\
\hline$K_{\mathrm{V}}(\mathrm{mm} / \mathrm{d})$ & 1.56 & 7.34 & 0.64 & 8.64 & 5.62 & 8.99 & 14.3 & 1.56 & 0.64 \\
\hline$K_{\mathrm{h}}(\mathrm{mm} / \mathrm{d})$ & 1.56 & 7.34 & 0.64 & 8.64 & 5.62 & 8.99 & 14.3 & 1.56 & 9.97 \\
\hline$E_{0}(\mathrm{kPa})$ & 2900 & 2400 & 1200 & 3500 & 9300 & 15,600 & 14,100 & 3000 & 1200 \\
\hline$v$ & 0.33 & 0.3 & 0.35 & 0.3 & 0.3 & 0.28 & 0.25 & 0.28 & 0.35 \\
\hline $\mathrm{C}^{\prime}(\mathrm{kPa})$ & 11 & 11 & 9 & 12 & 0 & 0 & 0 & 50 & 9 \\
\hline$\Phi^{\prime}\left({ }^{\circ}\right)$ & 15 & 14 & 15 & 18 & 27 & 28.9 & 32 & 18 & 15 \\
\hline$\Psi\left(^{\circ}\right)$ & 0 & 0 & 0 & 0 & 0 & 0 & 0 & 0 & 0 \\
\hline
\end{tabular}

Table 6. The soft soil creep model parameters.

\begin{tabular}{ccc}
\hline Parameters & Muddy Clay & Muddy Clay between Sand Wall \\
\hline$g_{\text {unsat }}\left(\mathrm{kN} / \mathrm{m}^{3}\right)$ & 17.84 & 17.84 \\
$g_{\text {sat }}\left(\mathrm{kN} / \mathrm{m}^{3}\right)$ & 18.15 & 18.15 \\
$K_{\mathrm{v}}(\mathrm{mm} / \mathrm{d})$ & 0.64 & 0.64 \\
$K_{\mathrm{h}}(\mathrm{mm} / \mathrm{d})$ & 0.64 & 9.97 \\
$\mathrm{l}^{*}$ & 0.051 & 0.051 \\
$\mathrm{k}^{*}$ & 0.01 & 0.01 \\
$\mathrm{~m}^{*}$ & 0.002 & 0.002 \\
$\mathrm{C}(\mathrm{kPa})$ & 9 & 9 \\
$\Phi\left(^{\circ}\right)$ & 15 & 15 \\
\hline
\end{tabular}

\subsection{Establishment of the Calculation Model}

To establish the geometric model, firstly, the drainage line should be used to simulate the drainage plate and establish the calculation model that is shown in Figure 8. The calculation model, established by equaling the sand-wall model, is shown in Figure 9. Meanwhile, feature points $\mathrm{C}$ and $\mathrm{H}$ are output by the results; the simulation of the construction process is shown in Table 7, and Day 0 is the beginning of the construction of the plastic drainage plate on 20 December 2010, combined with the actual construction.

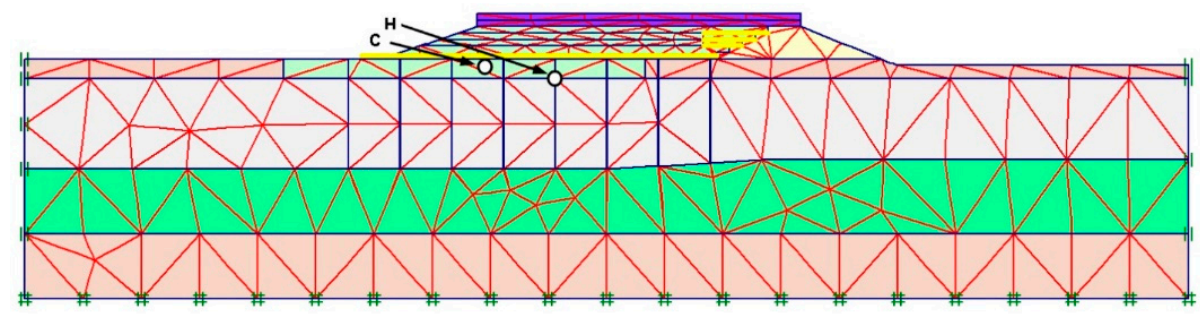

Figure 8. Drainage line model.

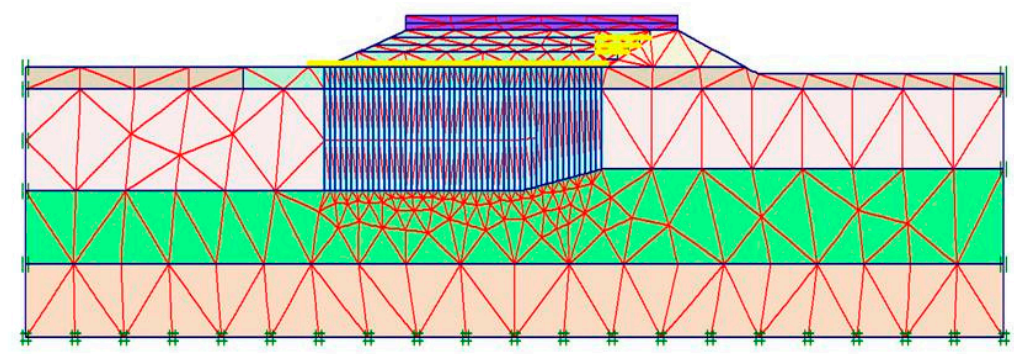

Figure 9. Equivalent sand-wall model ( $\mathrm{C}$ and $\mathrm{H}$ are two feature points). 


\subsection{Analysis of Numerical Results}

According to the finite element simulation, the stress strain diagram is obtained from different stages of the model. Figures 10 and 11 show the vertical and horizontal displacement of the cloud 1 year after the preloading of the drainage line model and equivalent sand-wall model.
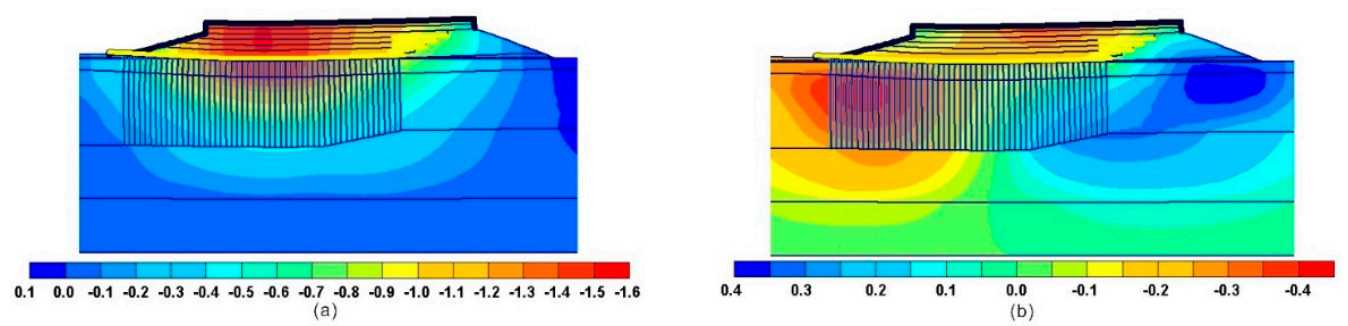

Figure 10. Vertical and horizontal displacement of the drainage line model after preloading by 1 year (m): (a) vertical displacement; (b) horizontal displacement.

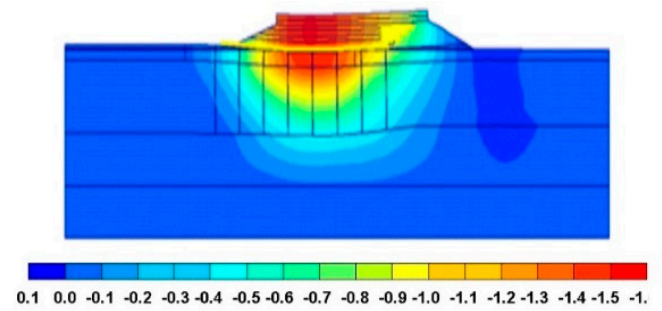

(a)

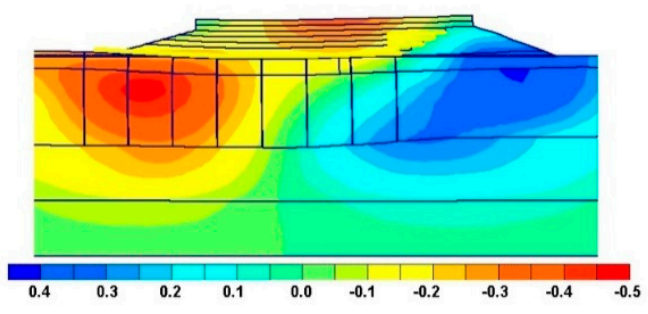

(b)

Figure 11. Vertical and horizontal displacement of the equivalent sand-wall model after preloading by 1 year (m): (a) vertical displacement; (b) horizontal displacement.

According to the practical positions of CJ1-1 and CJ1-2 in field, feature points $\mathrm{C}$ and $\mathrm{H}$ were chosen and the outputs of their vertical displacements are shown in Figure 12.

As is shown in Table 7, at 1 year after preloading, as calculated by the drainage line model, the vertical displacement of $\mathrm{C}$ is $-1465.97 \mathrm{~mm}$, and that of $\mathrm{H}$ is $-1433.42 \mathrm{~mm}$. If calculated by the equivalent sand-wall model, the vertical displacement of $\mathrm{C}$ is $-1460.87 \mathrm{~mm}$, and that of $\mathrm{H}$ is $-1427.22 \mathrm{~mm}$. After 1 year of operation, at the time when construction is completed, as calculated by the drainage line model, the vertical displacement of $C$ is $-1502.21 \mathrm{~mm}$, and that of $\mathrm{H}$ is $-1468.37 \mathrm{~mm}$. If calculated by the equivalent sand-wall model, the vertical displacement of $C$ is $-1497.00 \mathrm{~mm}$, and that of $\mathrm{H}$ is $-1462.17 \mathrm{~mm}$. After operating for 30 years as calculated by the drainage line model, the vertical displacement of $\mathrm{C}$ is $-1618.49 \mathrm{~mm}$, and that of $\mathrm{H}$ is $-1581.07 \mathrm{~mm}$. If calculated by the equivalent sand-wall model, the vertical displacement of $\mathrm{C}$ is $-1612.77 \mathrm{~mm}$, and that of $\mathrm{H}$ is $-1573.11 \mathrm{~mm}$. According to the project experience, the settlement after operating for 30 years to the time that the road damages are small, the settlement from the time that the operation begins to the time of operating for 30 years is nearly called the settlement after construction. As calculated by the drainage plate model, the settlement after construction of $\mathrm{C}$ is $146.18 \mathrm{~mm}$, and the vertical displacement of $\mathrm{H}$ is $142.08 \mathrm{~mm}$. If calculated by the equivalent sand-wall model, the settlement after construction of $\mathrm{C}$ is $146.64 \mathrm{~mm}$, and the vertical displacement of $\mathrm{H}$ is $141.31 \mathrm{~mm}$.

Table 7. Variation of settlements of the field test section.

\begin{tabular}{ccccc}
\hline \multirow{2}{*}{ Settlement $(\mathbf{m m})$} & \multicolumn{2}{c}{ Drainage Line Model } & \multicolumn{2}{c}{ Equivalent Sand-Wall Model } \\
\cline { 2 - 4 } & C Point & H Point & C Point & H Point \\
\hline 1 year after preloading & -1465.97 & -1433.42 & -1460.87 & -1427.22 \\
1 year of operation & -1502.21 & -1468.37 & -1497.00 & -1462.17 \\
30 years of operation & -1618.49 & -1581.07 & -1612.77 & -1573.11 \\
Settlement after construction & 146.18 & 142.08 & 146.64 & 141.31 \\
\hline
\end{tabular}


Therefore, using the drainage consolidation method to settle the soft soil embankment can achieve a good reinforcement effect and can effectively reduce the settlement after construction. Meanwhile, it can be seen that, as calculated by the drainage plate model, the settlement of the middle of the embankment is larger than that calculated by the equivalent sand-wall model, but the settlement curves of both models are highly similar. According to Figure 12, at a height of $7 \mathrm{~m}$, comparing the settlements by the drainage plate model and equivalent sand-wall model at the finish of preloading, 1 year after preloading, and 30 years after operation, shows a high degree of fitting.

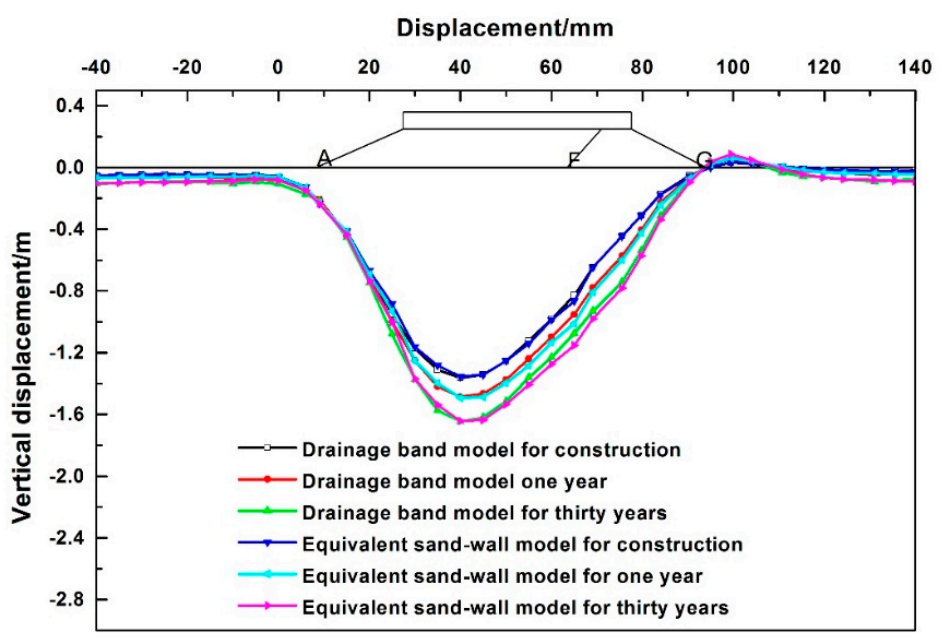

Figure 12. Settlement curve of the drainage plate model and equivalent sand-wall model at a height of $7 \mathrm{~m}$.

The calculation of the soft consolidation of the creep model of soft is taken from the equivalent sand-wall model and drainage line model, and it is feasible to use just the equivalent sand-wall model. According to the analysis in Figure 12, it can be seen that the maximum settlement of the embankment section happens at abscissa $40 \sim 45 \mathrm{~m}$ of the model, which is near feature point $\mathrm{C}$. Combined with Figure 13, this shows that the largest settlement of the section is near the middle of the new embankment. The settlement of the lateral toe of the slope of the new embankment is very small; the lateral toe of the slope of the old flood embankment is slightly uplifted, which means the settlement at the new filled embankment is very large and that makes the settlement at the joint of the old and new embankment very large. Because the old embankment has existed for a long time and has good integrity, the settlement happens at the joint part and the lateral toe of the slope of the old embankment achieves a slight uplift.

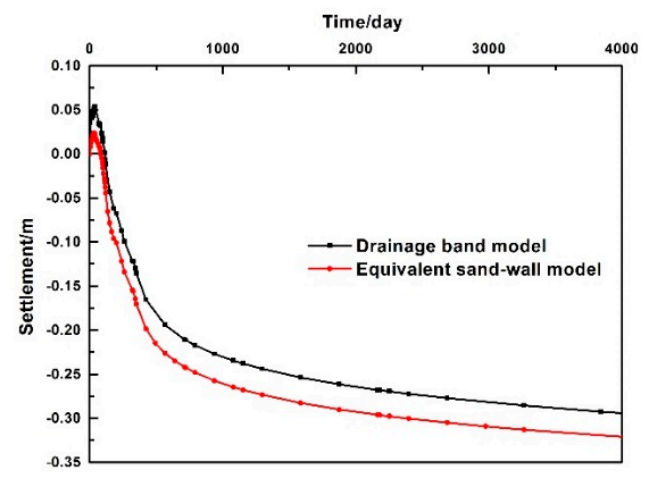

(a)

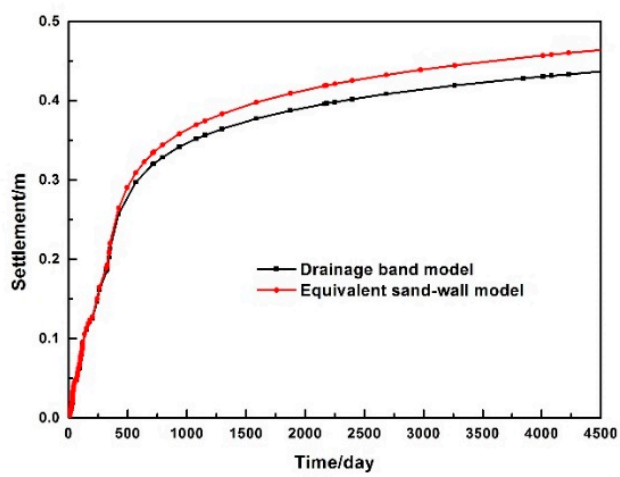

(b)

Figure 13. Horizontal displacement of the lateral toe of the slope: (a) A point; (b) G point.

According to the positions of the side pile and inclinometer tube that are at locale disposal, feature point A was chosen to output the horizontal displacement and to draw a graph, as shown in Figure 13. 
From Figure 13, we can see that in the beginning stages of setting the drainage plate, the horizontal displacement of A offsets to a positive direction of the model, which is medial of the embankment, while if calculated by the drainage plate model, during the first 35 days-which is after the beginning of the first layer of barged-in fill sand-the horizontal displacement of A offsets to a negative direction of the model, which is lateral of the embankment. The analysis shows that at the stage of setting the drainage plate, because there is suddenly a more vertical drainage channel in the soil, the water in the soft soil is excluded quickly in a short period of time under the pressure of the surrounding soil, which makes the soil in the treatment area compress, and the peripheral soil contract to the center of the embankment. After the beginning of filling, because of the settlement of the upper filled soil, the soft soil under the filling area starts to be squeezed and is extruded to the periphery, and the peripheral soil starts to laterally offset to the embankment. Then, according to Figure 13, the lateral toe of the old flood embankment $G$ offsets to the direction that deviates from the embankment after the beginning of the construction. As calculated by the drainage line model, the horizontal offset of the toe of the embankment is smaller than that calculated by the equivalent sand-wall model. Meanwhile, because it is affected by construction, the lateral horizontal offset of the new filled embankment offsets to the medial embankment first at the stage of setting the drainage plate, and this is the main reason for the final horizontal offset to be smaller than that of the old lateral embankment.

Figure 14 shows the deep horizontal displacement curves of the toe of the new filled embankment (A) and that of the old embankment (F). The ordinate is the same as that of the calculation model, and is called the WuSong height, which is an elevation system established with the sea level determined by the lowest tide level measured at Wusongkou tide gauge station in Shanghai from 1871 to 1900 . From Figure 14, we can see that the deep horizontal displacement shows an obvious transition and mutant near the interface of all soils, meaning that different prosperities of soil cause different horizontal displacements of different soils. The deep horizontal displacement of the soil under the new filled embankment reaches the maximum at a height of $0 \mathrm{~m}$ (nearly $7.5 \mathrm{~m}$ from the surface), but the maximal transition and mutant occur at nearly a height of $4 \mathrm{~m}$ of the interface, which means the maximal lateral displacement happens in a certain depth of soft soil under the surface. Meanwhile, it can be seen that the change laws of the deep horizontal displacement of the drainage line model and equivalent sand-wall model are very similar, but the horizontal displacement calculated by the drainage line model is relatively small.

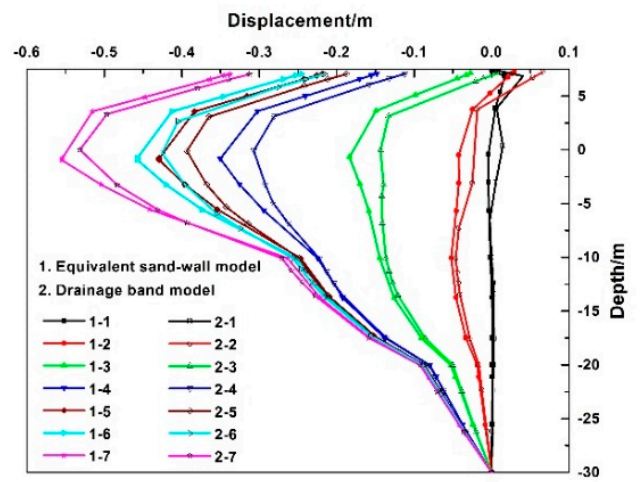

(a)

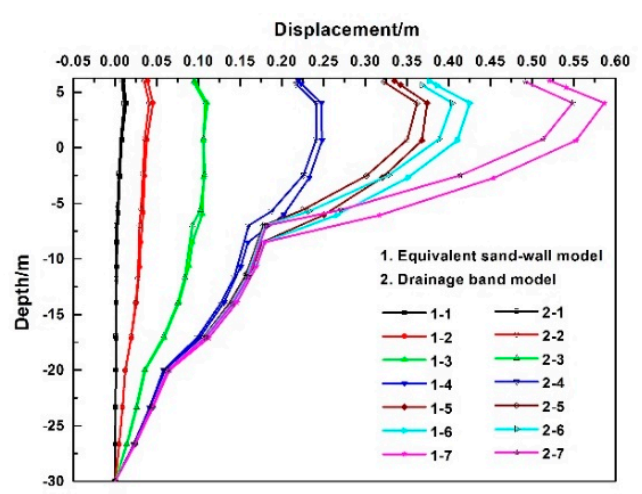

(b)

Figure 14. Horizontal displacement curves of the toe of the new subgrade and old embankment: (a) A point; (b) F point.

\subsection{Analysis and Comparison of Field Monitoring Data and Numerical Calculations}

Figure 15 shows the contrasting pattern of the field monitoring data and numerical calculation. According to Figure 15, the settlement dates of the field monitoring data and numerical calculation are similar, which means that using the drainage consolidation method to treat the soft soil foundation achieves a good outcome in practical engineering. The settlement date of the measurement is a 
little smaller than that of the numerical calculation, and the gap between them increases with time. The reason for the gap is because after a long time of working, the plastic drainage plates plug, fracture and so forth, impacting the normal operation of the drainage plates and causing lower drainage efficiency. However, the reduction of the drainage system efficiency was not considered in the numerical calculation, so the posterior settlement of the measured data is very small.

According to the calculation results, the deep horizontal displacement law obtained from the field monitoring is consistent with the numerical calculation results. Horizontal displacement occurs mainly in silty soft soil. Due to the poor mechanical properties of silty clay, this soil layer also has a certain horizontal displacement. Deep horizontal displacement mainly occurs in the soft soil layer at a certain depth from the surface, which is most likely to be damaged. Therefore, attention should be paid to it, and certain treatment measures should be taken to ensure the safety and stability of the embankment. At the same time, the field monitoring data and the numerical calculation data rule is similar. The pore pressure increases during the loading period and decreases gradually during the interval. After the completion of the construction, the excess pore water pressure gradually dissipates completely with the pre-loading of the reactor, and the pore water pressure remains at a low value and tends to be stable. In summary, the monitoring data of the embankment are consistent with the settlement deformation law of numerical calculation. The numerical simulation calculation is close to engineering practice and has high reliability.

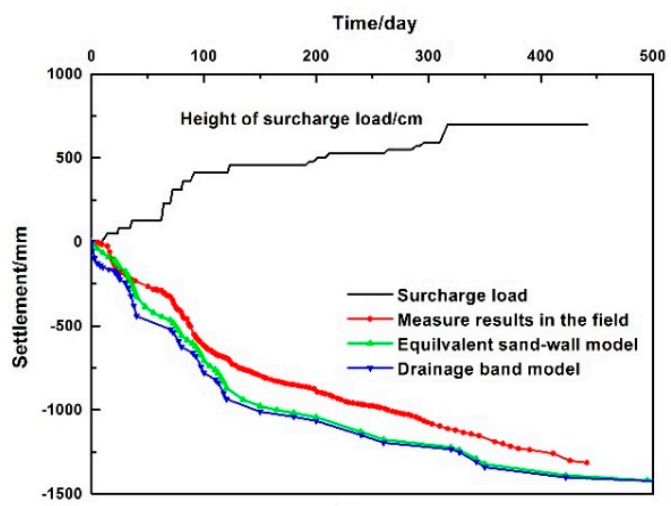

(a)

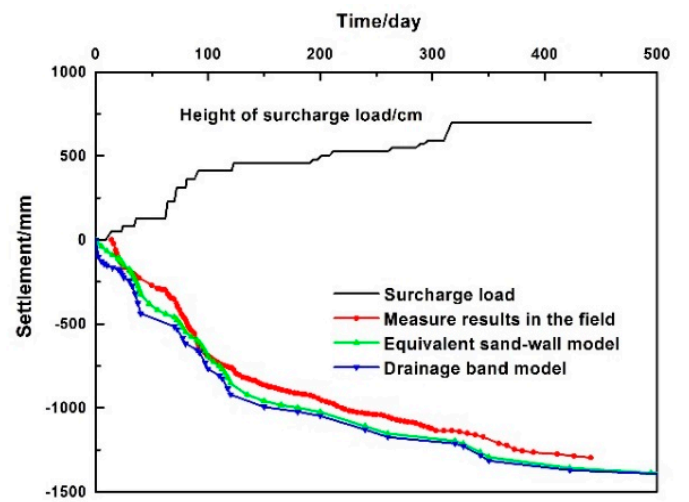

(b)

Figure 15. The settlement of the field monitoring test and numerical calculation: (a) CJ1-1; (b) CJ1-2.

\subsection{Settlement Prediction}

Generally, primary consolidation is the main part of total settlement. After primary consolidation settlement, when the excess pore water pressure dissipates, and on the condition that effective stress remains still, some soft clay under load will keep settling over time, and this settlement is called secondary consolidation settlement. The reason for secondary consolidation settlement is the rheology of soil, which includes creep deformation, stress relaxation, long-term strength, and the strain rate effect, and creep deformation is the most frequent factor so that deformation of the soil mass increases with time under the action of a constant load. Therefore, secondary consolidation settlement is treated as volume creep of soil.

Figure 16 shows the displacement diagram of the vertical increment of the model of the equivalent sand-wall in the first year of the operation. According to Figure 16, in the field test, the vertical displacement of soil layers except for the silt layer under the embankment is small. This means that by preloading for a while after construction of the road crust, settlement happens mainly in the silt clay. By analysis of the numerical calculation, the excess pore water pressure is $-0.79 \mathrm{kPa}$ after the pavement construction and dissipates to about 0 after that, as the settlement of the silt layer is creep settlement. Because the settlement later happens mainly in silt clay, after operating for 30 years the creep settlement is the same as the settlement after construction, as shown in Table 8. 


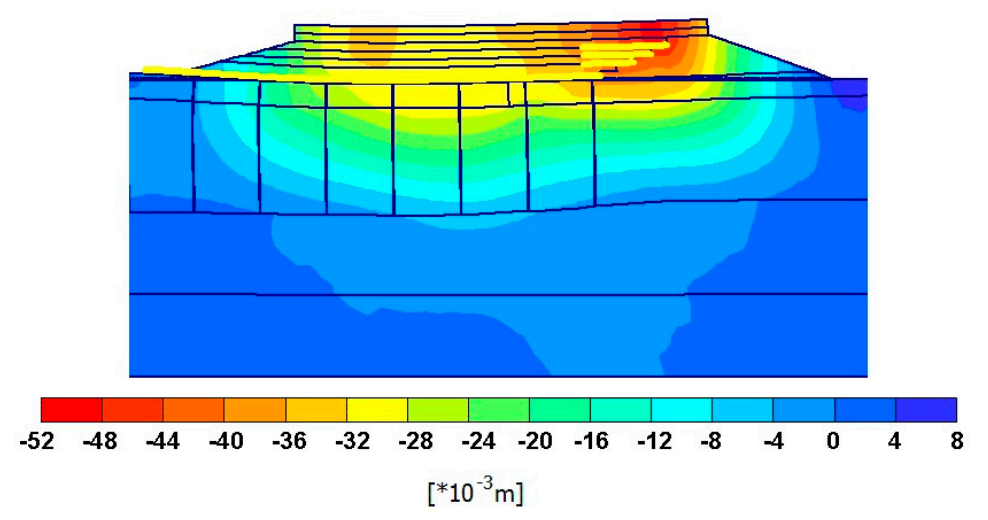

Figure 16. Displacement diagram of the vertical increment according to the model of the equivalent sand-wall in the first year of operation.

Table 8. The creep settlement according to the numerical calculation.

\begin{tabular}{lrcc}
\hline \multicolumn{2}{c}{ Drainage Line Model (mm) } & \multicolumn{2}{c}{ Equivalent Sand-Wall Model (mm) } \\
\hline C Point & F Point & C Point & F Point \\
\hline-146.18 & -142.08 & -146.64 & -141.31 \\
\hline
\end{tabular}

\section{Conclusions}

In this research regarding the measurement of integrated road-embankments in the Nanjing Riverside Avenue Project, many measures including field tests and numerical simulations were used, and the law of depositional deformation of the embankment under different drainage patterns and construction conditions was analyzed and obtained. The main conclusions are as follows:

(1) Using the drainage consolidation method to treat the soft soil foundation near water achieves a good effect, effectively reducing the settlement of soft soil foundation near water. During construction, the rate of construction and the preloading time of settlement are adjusted according to the feedback of the monitoring data, and as a result the embankment should be kept safe and stable, the consolidation time should be adequate, and the settlement after construction should be reduced. Because the silt clay is very deep, the settlement of the embankment will persist until a certain time after the finish of the filling construction. According to field monitoring data and numerical calculations, the settlement after construction and the total settlement are predicted on a test embankment, and every stage late is calculated, combined with specifications, so that the unloading time of the preloading soil is predicted. After this, advice is provided for the relevant engineering practices.

(2) The applicability of the numerical simulation is verified in that the model of the drainage line and equivalent sand-wall can be used to simulate the plastic drainage plate in treating the soft soil foundation, as the settlement deformations of both are highly similar. By combining this with field test data, it is shown that the settlement deformation law calculated using the numerical simulation is in agreement with the actual situation in the field. This means the model of the drainage line and equivalent sand-wall can be used to simulate the actual situation in the field. The model of the drainage line and equivalent sand-wall can be further used in subsequent simulations of the soft soil foundation, and will provide reference information for the design and construction of other projects.

Author Contributions: Data curation, J.W., J.L. and S.S.; Investigation, Z.S. and Y.B.; Methodology, J.W. and J.L.; Writing—original draft, J.W., Z.S. and J.L.; Writing—review \& editing, D.P.K.

Funding: This research is financially supported by the National Natural Science Foundation of China (Grant No. 41672258 \& 41472241).

Acknowledgments: We acknowledge the help of Ying Wang, Zhihao Chen and Fan Bu of School of Earth Sciences and Engineering, Hohai University.

Conflicts of Interest: The authors declare no conflict of interest. 


\section{References}

1. Han, J.; Huang, J.; Liu, S.Y.; Hong, Z.S. Stresses and deformations induced by widening of existing embankments over soft soils. In Proceedings of the International Symposium of Low Land Technology, Saga, Japan, 14-16 September 2006; pp. 201-205.

2. Wang, H.; Huang, X.M. Stress and deformation due to embankment widening with different treatment techniques. J. Cent. South Univ. 2011, 18, 1304-1310. [CrossRef]

3. Jin, S.W.; Yun, W.C.; Kim, Y.M.; Dong, S.K. Centrifuge modeling of differential settlement and levee stability due to staged construction of enlarged embankment. KSCE J. Civil Eng. 2014, 18, 1036-1046. [CrossRef]

4. Weng, X.; Wang, W. Influence of differential settlement on pavement structure of widened roads based on large-scale model test. J. Rock Mech. Geotech. Eng. 2011, 3, 90-96. [CrossRef]

5. Diab, A.; You, Z.; Yang, X.; Hasan, M.R.M. Towards an alternate evaluation of moisture-induced damage of bituminous materials. Appl. Sci. 2017, 7, 1049. [CrossRef]

6. Sun, L.; Wang, G.; Zhang, H.; Liu, L. Initiation and propagation of top-down cracking in asphalt pavement. App. Sci. 2018, 8, 774. [CrossRef]

7. Escolano, F.; Sánchez, J.R.; Pacheco-Torres, R.; Cerro-Prada, E. Strategies on reuse of clayey expansive soils as embankment material in urban development areas: A case study in new urbanized zones. App. Sci. 2018, 8,764. [CrossRef]

8. Varela, F.; Cerro-Prada, E.; Escolano, F. Preparation, characterization and modeling of unbound granular materials for road foundations. Appl. Sci. 2018, 8, 1548. [CrossRef]

9. Yokohama, S.; Miura, S.; Matsumura, S. Change in the hydromechanical characteristics of embankment material due to compaction state conditions. Soils Found. 2014, 54, 731-747. [CrossRef]

10. Weng, X.; Zhu, H.H.; Chen, J.; Liang, D.; Shi, B.; Zhang, C.C. Experimental investigation of pavement behavior after embankment widening using a fiber optic sensor network. Struct. Health Monit. 2015, 14, 46-56. [CrossRef]

11. Fan, C.C.; Hsieh, C.C. The mechanical behaviour and design concerns for a hybrid reinforced earth embankment built in limited width adjacent to a slope. Comput. Geotech. 2011, 38, 233-247. [CrossRef]

12. Mirjalili, M.; Kimoto, S.; Oka, F.; Hattori, T. Long-termconsolidation analysis of alarge-scale embankment constructionon soft clay deposits using an elasto-viscoplastic model. Soils Found. 2012, 52, 18-37. [CrossRef]

13. Cheung, Y.K.; Lee, P.K.K.; Xie, K.H. Some remarks on two and three dimensional consolidation analysis of sand-drained ground. J. Comput. Geotech. 1991, 12, 73-87. [CrossRef]

14. Yuan, J.B.; Liu, J.H. Application of dynamic compaction for poorly compacted embankment. J. Test. Eval. 2011, 39, 158-165.

15. Higo, Y.; Oka, F.; Kodaka, T.; Kimoto, S. Three-dimensional strain localization of water saturated clay and numerical simulation using an elasto-viscoplastic model. Philos. Mag. 2006, 86, 3205-3240. [CrossRef]

16. Han, J.; Oztoprak, S.; Parsons, R.L.; Huang, J. Numerical analysis of foundation columns to support widening of embankments. Comput. Geotech. 2007, 34, 435-448. [CrossRef]

17. Oka, F.; Tsai, P.; Kimoto, S.; Kato, R. Damage patterns of river embankments due to the 2011 off the pacific coast of tohoku earthquake and a numerical modeling of the deformation of river embankments with a clayey subsoil layer. Soils Found. 2012, 52, 890-909. [CrossRef]

18. Kamash, W.E.; Han, J. Displacements of column-supported embankments over soft clay after widening considering soil consolidation and column layout: Numerical analysis. Soils Found. 2014, 54, 1054-1069. [CrossRef]

19. Zhang, M.; Li, J.J.; Qin, C.K. Analysis and discussion on post-construction settlement of soft soil foundation treatment test section of highway. In Proceedings of the 2nd International Conference on Materials Science, Energy Technology and Environmental Engineering, Zhuhai, China, 28-30 April 2017; Volume 81.

(C) 2018 by the authors. Licensee MDPI, Basel, Switzerland. This article is an open access article distributed under the terms and conditions of the Creative Commons Attribution (CC BY) license (http:/ / creativecommons.org/licenses/by/4.0/). 